
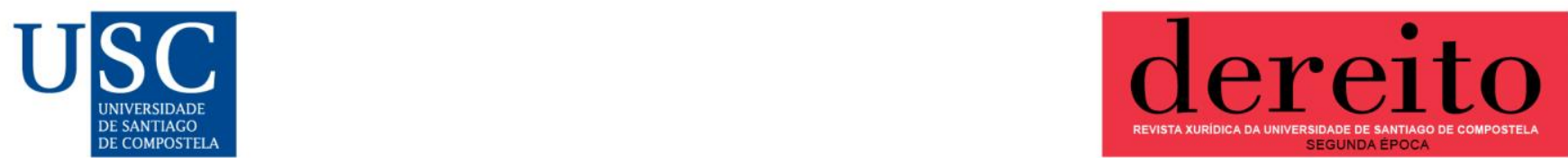

\title{
Empresário em nome individual versus sociedade unipessoal por quotas em Portugal
}

\author{
Empresario individual versus sociedade unipersonal en Portugal \\ Individual entrepreneur versus single-person limited company in Portugal
}

\section{José de Campos Amorim}

Professor Coordenador de Direito Fiscal, Instituto Superior de Contabilidade e Administração do Porto - Politécnico do Porto. j.camposamorim@gmail.com

\begin{abstract}
Resumo
Com o presente artigo pretendemos demonstrar que o planeamento fiscal é possível e desejável nas empresas de pequena dimensão. Em função da forma jurídica adotada, uma microempresa pode ficar sujeita ao regime de tributação proporcional das sociedades ou ao regime de tributação progressiva das empresas individuais, o que resulta em impostos diferentes a suportar conforme se aplique o regime geral ou o regime simplificado. Os empresários devem fazer uma avaliação dos critérios legais e fiscais para saber qual é a opção fiscalmente mais vantajosa.
\end{abstract}

Palavras-chave: Microempresas; Empresário em Nome Individual; Sociedade Unipessoal por Quotas; Fiscalidade

\section{Resumen}

Con este artículo pretendemos demostrar que la planificación fiscal es posible y deseable en pequeñas sociedades. Dependiendo de la forma legal adoptada, una microempresa puede estar sujeta al régimen fiscal proporcional para las sociedades o al régimen fiscal progresivo para los empresarios individuales, lo que resulta en impuestos diferentes dependiendo de si aplicamos el régimen general o el régimen simplificado. Los empresarios deben hacer una evaluación de los criterios legales y fiscales para averiguar qué opción fiscal es la más ventajosa.

Keywords: Micro-enterprises; Individual entrepreneur; Single-person limited company; Taxation.

\section{INTRODUÇÃO}

0 tecido empresarial português é constituído essencialmente por micro, pequenas e médias empresas (PME) que procuram fazer uma boa gestão dos seus recursos. As suas preocupações centram-se geralmente nas questões mais imediatas como a gestão de produção, gestão comercial e de tesouraria, e não na gestão fiscal, a qual é muitas vezes relegada para um segundo plano.

Tal como afirma Gunter Verheugen (2006), membro da Comissão Europeia Responsável pelas Empresas e a Indústria, "as micro, pequenas e médias empresas, são o motor da economia europeia. São uma fonte essencial de postos de trabalho, desenvolvem o espírito empresarial e a inovação na UE, sendo por isso cruciais para fomentar a competitividade e o emprego." ${ }^{1}$ De 
acordo com os dados disponibilizados pelo Instituto Nacional de Estatística (INE), 99\% são PME (tal como definido no Decreto-Lei no 372/2007, de 6 de novembro).

As PME têm, apesar de tudo, algumas desvantagens face às grandes empresas no que toca ao custo de cumprimento das obrigações fiscais e à obtenção de financiamento. 0 cumprimento das obrigações legais tem um peso elevado face à dimensão destas empresas. Estas entidades necessitariam de um sistema fiscal adequado às suas especificidades, ou seja, um sistema mais simples, de aplicação simplificada e de baixos custos de cumprimento (Lopes, 2009, 2012). Por isso, deveriam ser diminuídos os custos de contexto destas empresas a nível de custos administrativos e de cumprimento (Brys et al., 2011), mas também simplificado o cálculo dos impostos. Uma das soluções consistiria em simplificar o apuramento dos impostos e o conhecimento antecipado dos seus valores, criando, nomeadamente, um regime simplificado baseado em coeficientes de base técnico-científica.

Existem vários estudos e relatórios que foram produzidos no contexto Português, ao longo dos anos, que têm vindo a apontar para um excessivo grau de complexidade do sistema fiscal, bem como para a necessidade de o simplificar (Martins, 2005; Santos \& Martins, 2009; Lopes, 2012; Borrego et al., 2016a).

Pretendemos com este artigo, ajudar os pequenos empresários e quem os acompanha a tomar as opções que lhe proporcionem, dentro da legalidade, a maior poupança fiscal em sede de tributação do rendimento, permitindo às empresas tornarem-se mais competitivas a nível nacional e internacional.

Perante as questões colocadas, propomos que este artigo seja dividido em quatro secções, a primeira por esta introdução. A segunda secção procedesse ao enquadramento das implicações fiscais da escolha da forma jurídica, de seguida a análise aos regimes simplificados de tributação do rendimento e por fim, na última secção, as principais conclusões.

\section{AS FORMAS JURÍDICAS NAS MICROEMPRESAS}

\subsection{A forma societária e não societária}

O sujeito passivo pode escolher entre várias formas jurídicas, quer societárias, quer não societárias, para desenvolver a sua atividade, dependendo do enquadramento fiscalmente menos oneroso. Assiste ao contribuinte optar "entre as várias soluções que lhe são proporcionadas pelo elemento jurídico, aquela que, por ação intencional ou emissão do legislador, está acompanhada de menos encargos fiscais" (Sanches, 2006, p. 26). Os contribuintes podem adotar uma solução que lhe seja fiscalmente mais vantajosa, desde de que o faça dentro dos limites legais, isto é, no quadro de um planeamento fiscal intra legem.

As microempresas podem ser constituídas sob a forma de Sociedades por Quotas (SQ), ou sociedades Unipessoais por Quotas (SUQ) ou ainda sob a forma não societária de Empresário em Nome Individual (ENI), os quais se distinguem um do outro pela natureza da responsabilidade social e tributária. 0 empresário em nome individual - anteriormente designado por firma individual - é uma pessoa singular que desenvolve uma atividade de natureza comercial, industrial ou agrícola, de forma independente, não constituída sob a forma de sociedade mas sujeita ao regime de tributação em sede de categoria B do IRS. No caso de serviços prestados a uma só entidade, exceto no caso de prestação de serviços efetuada a uma sociedade de transparência fiscal, o empresário pode optar, em cada ano, na declaração Modelo 3, pela tributação de acordo com as normas estabelecidas para a categoria A.

Relativamente à figura de sociedade unipessoal por quotas, esta é constituída por um único sócio, pessoa singular ou coletiva, que tem a vantagem de poder proteger o seu património pessoal e familiar, 
uma vez que o sócio deixa de responder ilimitadamente pelas dívidas da sociedade. A determinação do rendimento coletável pode ocorrer de duas formas distintas: regime simplificado ou contabilidade.

\begin{tabular}{|c|c|c|c|c|}
\hline & \multicolumn{2}{|c|}{ ENI } & \multicolumn{2}{|c|}{ Sociedade Unipessoal por Quotas } \\
\hline & \multicolumn{2}{|c|}{$\begin{array}{l}\text { Pessoa singular que desenvolve uma } \\
\text { atividade de natureza comercial, } \\
\text { industrial ou agrícola, de forma } \\
\text { independente. }\end{array}$} & \multicolumn{2}{|c|}{$\begin{array}{l}\text { Constituição de uma empresa como } \\
\text { sociedade, com um único sócio, podendo ser } \\
\text { uma pessoa singular ou coletiva. }\end{array}$} \\
\hline Tributação & \multicolumn{2}{|c|}{ Sujeito a IRS } & \multicolumn{2}{|c|}{ Sujeito a IRC } \\
\hline $\begin{array}{c}\text { Responsabilida } \\
\text { de tributária }\end{array}$ & \multicolumn{2}{|c|}{ Responsabilidade ilimitada } & \multicolumn{2}{|c|}{ Responsabilidade limitada } \\
\hline Capital Social & \multicolumn{2}{|c|}{ Não existe } & \multicolumn{2}{|c|}{ Mínimo $1 €$} \\
\hline Designação & \multicolumn{2}{|c|}{ Nome civil ou abreviado } & \multicolumn{2}{|c|}{$\begin{array}{l}\text { "Sociedade unipessoal" ou "unipessoal" } \\
\text { antes da abreviatura "Lda" }\end{array}$} \\
\hline Regime fiscal & $\begin{array}{c}\text { Regime } \\
\text { simplificado }\end{array}$ & Geral & $\begin{array}{l}\text { Regime } \\
\text { simplificado }\end{array}$ & Geral \\
\hline $\begin{array}{l}\text { Matéria } \\
\text { coletável }\end{array}$ & $\begin{array}{l}\text { Aplicação } \\
\text { coeficientes }\end{array}$ & Lucro/prejuízo & $\begin{array}{l}\text { Aplicação } \\
\text { coeficientes }\end{array}$ & Lucro/prejuízo \\
\hline Prejuízos fiscais & $\begin{array}{l}\text { Não permite a } \\
\text { dedução de } \\
\text { prejuízos fiscais }\end{array}$ & $\begin{array}{l}\text { Reportado aos } 12 \\
\text { anos seguintes } \\
\text { àquele a que } \\
\text { respeita }\end{array}$ & $\begin{array}{l}\text { Não permite a } \\
\text { dedução de } \\
\text { prejuízos fiscais }\end{array}$ & $\begin{array}{l}\text { Reportado aos } 12 \text { anos } \\
\text { seguintes àquele a que } \\
\text { respeita }\end{array}$ \\
\hline $\begin{array}{l}\text { Tributação } \\
\text { autónoma }\end{array}$ & $\begin{array}{l}\text { Parcialmente } \\
\text { excluído. Art. } \\
\text { 73. }{ }^{\circ} \text {, n. } \stackrel{\circ}{ } 8\end{array}$ & Art. $93^{\circ}$ & Art. $98^{\circ}$ & Art. $=88^{\circ}$ \\
\hline Derrama & Não existe & Não existe & Não existe & Existe \\
\hline Coleta & $\begin{array}{c}\text { Taxas } \\
\text { progressivas }\end{array}$ & $\begin{array}{c}\text { Taxas } \\
\text { progressivas }\end{array}$ & $\begin{array}{c}\text { Taxas } \\
\text { proporcionais }\end{array}$ & Taxas proporcionais \\
\hline
\end{tabular}

A principal diferença entre SQ/SUQ e os ENI reside no facto de as sociedades serem tributadas a uma taxa proporcional e os ENI sujeitos a uma tributação progressiva, de acordo com a categoria B do IRS, o que significa que quanto mais elevado for o rendimento, maior será a taxa de tributação aplicável a todo esse rendimento, com a agravante de que os rendimentos da categoria B são englobados aos restantes rendimentos do titular e do seu agregado familiar, conforme o art. ${ }^{\circ} 2^{\circ}$ do CIRS, o que tem por efeito de aumentar o escalão e de sujeitar a totalidade dos rendimentos a taxas mais elevadas. Já não acontece no caso das sociedades, em que os seus resultados são tributados isoladamente às taxas previstas do art. - 87a do CIRC, sendo que as entidades que preenchem os requisitos de qualificação como PME beneficiam para 
os primeiros $25.000,00 €$ de matéria coletável da redução da taxa para $17 \%$ e o remanescente da matéria coletável à taxa geral de $21 \%$.

A forma de cálculo do lucro tributável e da matéria coletável é semelhante, uma vez que o art. ${ }^{3} 2^{\circ}$ do CIRS remete a tributação dos rendimentos gerados pelos ENI para o CIRC, com as

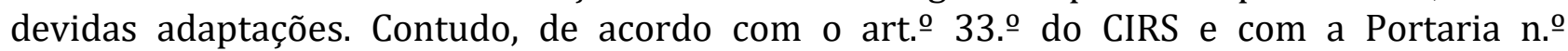
1041/2001 de 28 de agosto, verificamos a existência de um conjunto de limitações:

\begin{tabular}{l}
\hline Não-aceitação das remunerações do empresário a qualquer título \\
Número máximo de viaturas em função do número de trabalhadores \\
Dedução até 25\% dos encargos da renda, água, eletricidade e outros do imóvel \\
onde o empresário habita \\
Distribuição de encargos com outros profissionais, quando partilham o mesmo \\
espaço físico no exercício da sua atividade
\end{tabular}

Das limitações referidas na tabela anterior, destaca-se a não dedução das remunerações, contabilizadas a qualquer título, do empresário, remunerações estas que nas pequenas empresas sob a forma societária são encargos dedutíveis no contexto de uma sociedade enquanto remunerações do sócio, sendo elas consideradas pelo sócio como rendimentos de trabalho dependente - categoria A do IRS (art. $2^{\circ}$ n. 1 al.a)) do CIRS). Acabam até, em alguns casos, por não ser sujeitos a tributação, no todo ou em parte, devido a:

- dedução especifica de 4.104,00€, prevista no art.ำ 25ํำ n. 1 al.a) do CIRS;

- mínimo de existência (art. ${ }^{2}$ 0 do CIRS), que implica um mínimo de rendimento líquido de 9.215,01€ - 1,5 x 14 x IAS (438,81€) - para titulares de rendimentos de trabalho dependente e/ou pensões, o que implica a total isenção para rendimentos até ao limite daquele montante.

A dedução de prejuízos fiscais é muito semelhante em ambas as situações. 0 resultado líquido negativo apurado através da categoria B pode ser reportado aos 12 anos seguintes àquele a que respeita (art.. 55을 do CIRS), à semelhança do art. $52^{\circ}$ do CIRC.

Nas tributações autónomas (TA), temos diferenças significativas, considerando o previsto no art. ${ }^{\circ}$ 73. ${ }^{\circ}$ CIRS e no art. ${ }^{\circ}$ 88.. do CIRC, as taxas de tributação são diferentes e os valores que definem a sua aplicação também, tal como descritas abaixo: 


\begin{tabular}{|c|c|c|c|c|c|}
\hline Tributação autónoma & \multicolumn{2}{|c|}{ IRS } & \multicolumn{3}{|c|}{ IRC } \\
\hline Despesas não documentadas & \multicolumn{2}{|c|}{$50 \%$} & \multicolumn{3}{|c|}{$50 \%$ ou $70 \%$} \\
\hline $\begin{array}{l}\text { Encargos com viaturas ligeiras de } \\
\text { passageiros ou mistas, motos e } \\
\text { motociclos }^{2}\end{array}$ & $\begin{array}{c}\mathrm{VA}< \\
20.000 €\end{array}$ & $\begin{array}{c}V A> \\
20.000 €\end{array}$ & $\begin{array}{c}\mathrm{VA}< \\
27.500 €\end{array}$ & $\begin{array}{l}\mathrm{VA} \geq \\
27.500 € \\
<35.000 €\end{array}$ & $\begin{array}{c}V A \geq \\
35.000 €\end{array}$ \\
\hline Híbridos Plug-in & $10 \%$ & $20 \%$ & $10 \%$ & $27,50 \%$ & $35,00 \%$ \\
\hline GPL/GNV & $5 \%$ & $10 \%$ & $5 \%$ & $10 \%$ & $17,50 \%$ \\
\hline \multirow{2}{*}{ Energia elétrica } & $7,50 \%$ & $15 \%$ & $7,50 \%$ & $15 \%$ & $27,50 \%$ \\
\hline & $0 \%$ & $0 \%$ & $0 \%$ & $0 \%$ & $0 \%$ \\
\hline Despesas de representação & \multicolumn{2}{|c|}{$10 \%$} & \multicolumn{3}{|c|}{$10 \%$} \\
\hline $\begin{array}{l}\text { Despesas pagas ou devidas, a } \\
\text { qualquer título, a pessoas singulares } \\
\text { ou coletivas residentes fora do } \\
\text { território português e aí submetidas a } \\
\text { um regime fiscal claramente mais } \\
\text { favorável }\end{array}$ & \multicolumn{2}{|c|}{$35 \%$} & & \multicolumn{2}{|l|}{$35 \%$ ou $55 \%$} \\
\hline $\begin{array}{l}\text { Encargos dedutíveis relativos a ajudas } \\
\text { de custo e a compensação pela } \\
\text { deslocação em viatura própria do } \\
\text { trabalhador }\end{array}$ & \multicolumn{2}{|c|}{$5 \%$} & & \multicolumn{2}{|l|}{$5 \%$} \\
\hline $\begin{array}{l}\text { Lucros distribuídos por entidades } \\
\text { sujeitas a IRC a sujeitos passivos que } \\
\text { beneficiam de isenção total ou parcial }\end{array}$ & & & \multicolumn{3}{|c|}{$23 \%$} \\
\hline $\begin{array}{l}\text { Os gastos ou encargos relativos a } \\
\text { indemnizações, bónus e outras } \\
\text { remunerações variáveis pagas a } \\
\text { gestores, administradores ou } \\
\text { gerentes. }\end{array}$ & & & \multicolumn{3}{|c|}{$35 \%$} \\
\hline
\end{tabular}

É de realçar o facto de as tributações autónomas em IRS serem mais leves, em termos gerais, comparativamente com as do IRC, nomeadamente a TA para as viaturas ligeiras de passageiros ou mistas, a tributação em IRS ascende no máximo a $20 \%$ enquanto em IRC a taxa máxima é de $35 \%$. 
No caso das sociedades, acresce ao valor da coleta, a derrama municipal, cuja taxa é determinada pelo município, até ao limite máximo de 1,5\%, podendo coexistir uma taxa reduzida para empresas que obedeçam aos critérios estabelecidos pelos mesmos. A derrama incide sobre o lucro tributável do exercício, antes da dedução de prejuízos fiscais reportáveis.

Há ainda a destacar o facto de a tributação dos rendimentos dos ENI, apesar de englobados aos restantes rendimentos, ser apurada exclusivamente em sede de IRS, ao contrário das sociedades cuja tributação dos lucros ocorre em duas fases, as quais podem dar origem a uma dupla tributação económica: a primeira fase opera aquando da obtenção de lucros, que são tributados em sede de IRC, e a segunda fase aquando da distribuição dos mesmos, que são tributados na esfera dos sócios em IRS, sendo a sua tributação sujeita a retenção na fonte a título definitivo à taxa liberatória de $28 \%$ segundo a al. c) do n. 0 1 do art. ${ }^{\circ} 71^{\circ}$ do CIRS, aplicável pela sociedade geradora dos resultados no momento do pagamento ou da colocação à disposição dos lucros distribuídos. A não ser que o sócio opte, de acordo com o n. 8 do art.o 71. ${ }^{\circ}$ do CIRS, pelas taxas progressivas do art. o 68. - do CIRS, obrigando para isso ao englobamento da totalidade dos rendimentos desta categoria, passando a retenção na fonte liberatória e definitiva a ser um adiantamento por conta do imposto. No caso de englobamento, os lucros devidos por pessoas coletivas sujeitas e não isentas do IRC são, conforme o art. ${ }^{\circ} 40 .{ }^{\circ}-$ A do CIRS, considerados em apenas $50 \%$ do seu valor.

Lucros distribuídos

\begin{tabular}{|c|c|c|}
\hline $\begin{array}{c}\text { Opção sem } \\
\text { englobamento }\end{array}$ & $\begin{array}{l}\text { Sociedade retém na fonte } \\
28 \% \text { - taxa liberatória }\end{array}$ & Dispensa de declarar os lucros distribuídos \\
\hline $\begin{array}{c}\text { Opção com } \\
\text { englobamento }\end{array}$ & $\begin{array}{l}\text { Sociedade retém na fonte } \\
28 \% \text { - taxa liberatória }\end{array}$ & $\begin{array}{l}\text { Declara os lucros distribuídos } \\
\text { Engloba } 50 \% \text { dos lucros - art.. } 40^{\circ}-\mathrm{A}-\mathrm{e} 100 \% \\
\text { do imposto retido pela sociedade } \\
0 \text { rendimento fica sujeito às taxas gerais e } \\
\text { progressivas do art. } 68^{\circ}\end{array}$ \\
\hline
\end{tabular}

Relativamente à forma jurídica das microempresas, há três situações que importa aqui confrontar entre si, com o objetivo principal de elegermos a que apresenta uma carga fiscal mais leve:

a) a tributação como empresário/profissional individual;

b) a tributação como sociedade, seja ela por quotas ou unipessoal por quotas, sem englobamento dos lucros recebidos;

c) e a tributação como sociedade, igual à anterior, com englobamento dos lucros recebidos.

Não são consideradas aqui as atividades desenvolvidas por profissionais, de acordo com a lista prevista no art.o $151^{\circ}$ do CIRS, uma vez que quando desenvolvidas sob a forma societária, estas atividades enquadram-se em termos fiscais no regime das sociedades transparentes,

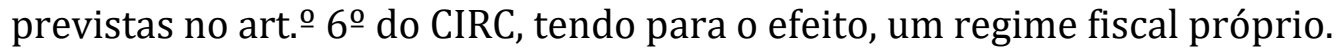




\subsection{Vantagens e desvantagens dos regimes de tributação}

Perante os diferentes regimes, apresentamos uma ilustração que permite compreender as vantagens e desvantagens fiscais dos regimes de tributação aplicáveis às SQ, SUQ ou ainda aos ENI.

Suponhamos, a título meramente ilustrativo, que um determinado contribuinte, Sr. António, residente no Porto, solteiro, sem dependentes, exerce a sua atividade, por conta própria, de compra e venda de produtos alimentares, e não auferiu outros rendimentos para além dos resultantes da sua atividade. Face ao elevado montante de imposto a pagar, o Sr. António pretende saber qual a situação fiscalmente mais vantajosa entre constituir uma SUQ ou manterse como ENI. Na eventualidade de constituir uma sociedade, o contribuinte pretende ser gerente da mesma e ser remunerado, prevendo receber a remuneração mínima garantida de $600,00 € /$ mês, a qual totaliza ao longo do ano 8.400,00 €, assim como serão distribuídos $70 \%$ dos lucros ao sócio. De forma a simplificar, considera-se como distribuída a referida percentagem do resultado fiscal.

Sabe-se que o Sr. António adquiriu em 2017, uma viatura ligeira de passageiros, movida a gasóleo, no valor de 26.000,00€ (sem IVA). 0 inventário no final do ano é nulo, uma vez que tudo o que foi adquirido foi vendido. No ano de 2021, o valor de vendas foi de 194.070,59€, as compras de 154.960,00 €, os encargos com a viatura de 1.937,00€ (conservação 240,50€, gasóleo 1.227,25€, seguro 258€, IUC 54,80€, portagens 156,45€ e amortização 0,00€), a despesa com o contabilista certificado $200,00 €$ /mês e as outras despesas de 12.443,25€.

- Hipótese 1: Forma jurídica não societária

- Hipótese 2: Forma jurídica societária, sem englobamento dos lucros distribuídos;

- Hipótese 3: Forma jurídica societária, com opção de englobamento dos lucros distribuídos.

O objetivo é calcular, nas três opções, o valor da coleta, acrescido de eventuais tributações autónomas, para posteriormente, comparar a hipótese que, no seu conjunto, apresenta um menor imposto a pagar ao Estado. 
Rendimento coletável: $194.070,59$ - 154.960 - 1.937 - 2.400 - 12.443,25 = 22.330,34€

Tributação autónoma da viatura ligeira de passageiros (art.o 73으 do CIRS): 1.937,00€ x 20\% = 387,40€

Coleta: $(20322 \times 22,621 \%)+[(22.330,34-20322) \times 35 \%]=5.299,95 €$ (art.ㅇ $68^{\circ}$ do CIRS)

Total de imposto Hip. 1: $387,40 €+5.299,95 €=5.687,35 €$

Hipótese 2 - SUQ com distribuição de lucros sem opção pelo englobamento

\begin{tabular}{|c|c|}
\hline SUQ & 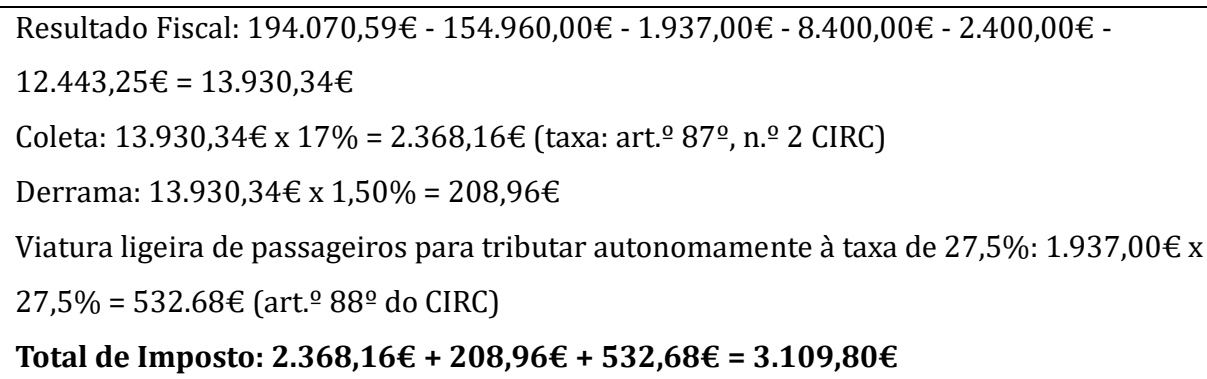 \\
\hline \multirow{2}{*}{ Distribuição } & $\begin{array}{l}\text { Tributação do lucro distribuído, por retenção na fonte: } \\
\text { Valor distribuído: } 13.930,34 € \times 70 \%=9.751,24 € \\
\text { Retenção na fonte: } 9.751,24 € \times 28 \%=2.730,35 € \text { (art.o } 71 \text { do CIRS) }\end{array}$ \\
\hline & $\begin{array}{l}\text { Rendimento categoria A } \\
\text { Rendimento coletável: } 600,00 € \times 14 \text { meses }=8.400,00 € \\
\text { Mínimo de existência - tributação: Zero }\end{array}$ \\
\hline
\end{tabular}

Hipótese 3 - SUQ com distribuição de lucros com opção pelo englobamento

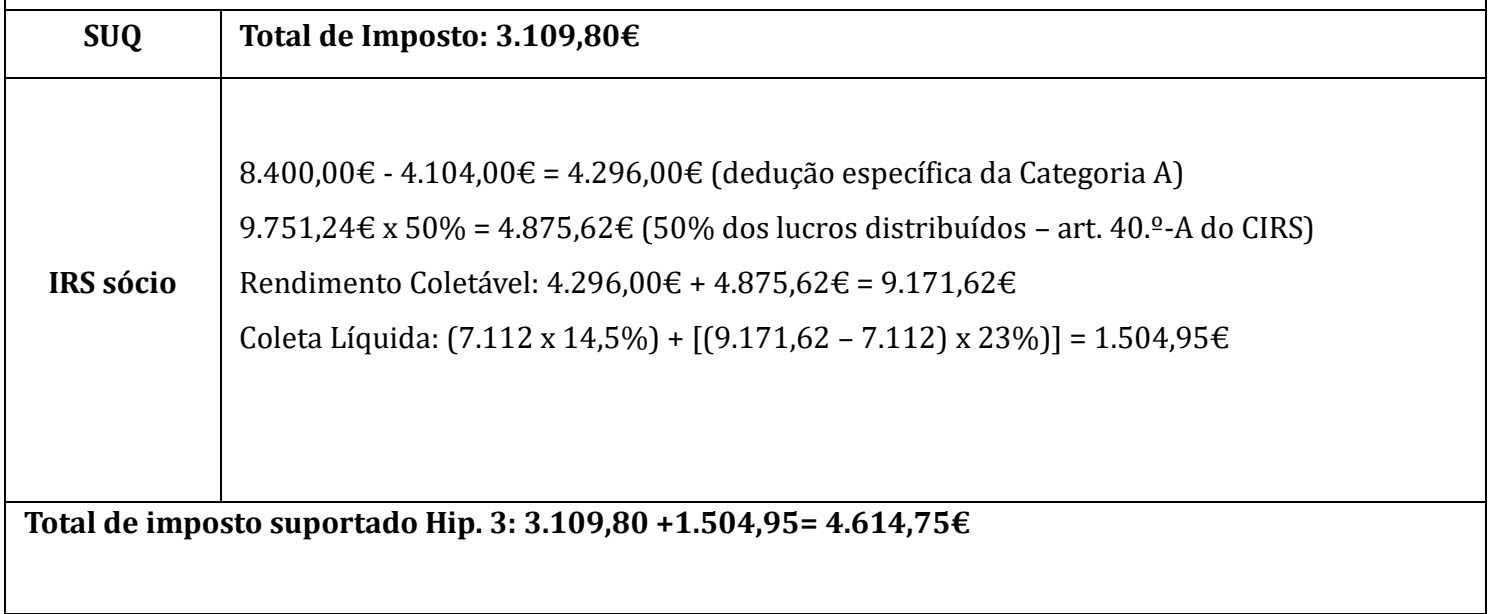


Concluímos que a hipótese n. 3 é aquela que proporciona uma maior vantagem fiscal ao Sr. António na medida em que permite considerar como gasto fiscalmente aceite a remuneração do sócio e minimizar o efeito da dupla tributação económica de lucros distribuídos.

\subsection{As especificidades do regime simplificado}

0 regime simplificado de tributação surgiu com a Lei n. ${ }^{\circ}$ 30-G/2000, de 29 de dezembro, e entrou em vigor a 1 de janeiro de 2001, 12 anos após o início da vigência do CIRS e do CIRC. 0 regime simplificado para os ENI mantêm-se em vigor até à data, apesar de ter sofrido várias alterações ao longo dos anos. Quanto ao regime simplificado para as sociedades, este foi suspenso em 2009, revogado pela Lei n. - 3-B/2010 de 28 de abril e, novamente implementado com a reforma do IRC de 2014, através da Lei n. $-2 / 2014$ de 16 de janeiro (Antunes, 2014).

É um método alternativo à contabilidade geral, pelo qual os ENI e as sociedades que preencham os correspondentes requisitos ficam dispensados de contabilidade. Contudo, o regime simplificado de IRS é diferente do regime simplificado de IRC quanto ao seu acesso e permanência, quanto aos requisitos, quanto aos coeficientes para o apuramento do rendimento tributável ou da matéria coletável. A dedução ao rendimento que decorre da aplicação dos coeficientes previstos nas alíneas b) e c) do n. ${ }^{\circ} 1$ do artigo 31. do CIRS (respetivamente, o coeficiente de 0,75 aplicável aos rendimentos das atividades profissionais especificamente previstas no artigo 151. e o coeficiente de 0,35 aplicável aos rendimentos de prestações de serviços não previstos nas alíneas anteriores) está parcialmente condicionada à verificação de despesas e encargos efetivamente suportados, da qual pode resultar um acréscimo ao rendimento tributável se a diferença entre os $15 \%$ dos rendimentos brutos das prestações de serviços e o somatório das importâncias comprovadamente suportadas nas matérias previstas nas al. a) a f) do n. ${ }^{\circ} 13$ do artigo 31 for positiva. Para beneficiar desta dedução ao rendimento, os empresários e profissionais devem afetar as despesas e encargos à atividade empresarial ou profissional, sob pena de acréscimo ao rendimento tributável.

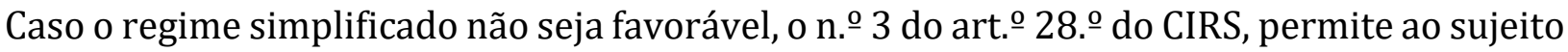
passivo enquadrado no regime simplificado a possibilidade de optar pela determinação dos rendimentos com base na contabilidade. Esta opção deve ser feita na declaração de início de atividade, ou até ao fim do mês de março do ano em que pretendem alterar a forma de determinação do rendimento, mediante apresentação de uma declaração de alterações. Tal como referem Alves et al. (2012), a opção pelo regime de tributação é maioritariamente realizada pelos contabilistas certificados, de acordo com os limites legalmente estabelecidos. Em sede de IRS, o regime simplificado de tributação é aplicável aos sujeitos passivos que não tenham ultrapassado no período de tributação imediatamente anterior um montante anual ilíquido de 200.000,00 € ou este montante seja ultrapassado num único exercício, em montante superior a 25\% (art.o 28. , n.. 2 e 6 do CIRS).

Verificados estes factos, ficam abrangidos pelo regime de contabilidade a partir do início do período de tributação seguinte àquele em que ocorreu a sua constatação. Em IRC cessa quando deixa de se verificar qualquer um dos requisitos anteriormente referidos ou quando o sujeito passivo não cumpra a obrigação de comunicação das faturas e/ou quando renuncie a sua aplicação.

Já em IRC, impõe-se aos sujeitos passivos que tenham obtido, no período de tributação imediatamente anterior, um montante anual ilíquido de rendimentos não superior a $200.000,00 €(\mathrm{a})$; um total de balanço relativo ao período de tributação imediatamente anterior não superior a 500.000,00 € (b); não estejam legalmente obrigados à revisão oficial de contas 
(c); o respetivo capital social não seja detido em mais de $20 \%$, direta ou indiretamente, nos termos do n.․ 6 do art.o 69. ${ }^{\circ}$ CIRC, por entidades que não preencham algumas das condições previstas nas alíneas anteriores, exceto quando sejam sociedades de capital de risco ou investidores de capital de risco (d); adotem o regime de normalização contabilística para microentidades aprovado pelo DL n. ${ }^{0}$ 36A/2011, de 9 de março (e) e não tenham renunciado à aplicação do regime nos três anos anteriores, com referência à data em que se inicia a aplicação do regime (f). Encontram-se excluídos deste regime, todos os sujeitos passivos abrangidos pelo regime de transparência fiscal (art. ${ }^{\circ}$ 6. $\mathrm{CIRC}$ ), assim como os sujeitos passivos abrangidos pelo regime especial de tributação dos grupos de sociedades (art. 69. CIRC).

Os coeficientes para o apuramento do rendimento tributável ou da matéria coletável, constantes do art. ${ }^{\circ} 31^{\circ}$ CIRS e do art.ㅇ $86^{\circ}-\mathrm{B}$ do CIRC, respetivamente.

\begin{tabular}{|c|c|c|}
\hline \multirow[b]{2}{*}{ Tipos de Rendimento } & \multicolumn{2}{|c|}{ Coeficientes } \\
\hline & $\begin{array}{l}\text { Art.o } \\
\text { 31o } \\
\text { CIRS }\end{array}$ & Art. 86--B CIRC \\
\hline Vendas e serviços prestados de restauração, hotelaria, bebidas e afins & 0,15 & $0,04^{* *}$ \\
\hline Serviços especificamente incluídos na lista do art. $\stackrel{\circ 151^{\circ}}{\text { do }}$ CIRS & $0,75^{*}$ & 0,75 \\
\hline Outras prestações de serviços & $0,35^{*}$ & $0,1^{* *}$ \\
\hline $\begin{array}{l}\text { Rendimentos provenientes de contratos que tenham por objeto a cessão ou } \\
\text { utilização temporária da propriedade intelectual ou industrial, aos } \\
\text { rendimentos de capitais, ao resultado positivo de rendimentos prediais, ao } \\
\text { saldo positivo das mais/menos-valias e aos restantes incrementos } \\
\text { patrimoniais }\end{array}$ & 0,95 & \\
\hline Subsídios não destinados à exploração; & 0,3 & 0,3 \\
\hline $\begin{array}{l}\text { Subsídios destinados à exploração e restantes rendimentos da categoria } B \text { não } \\
\text { previstos nas alíneas anteriores }\end{array}$ & $0,1^{*}$ & \\
\hline $\begin{array}{l}\text { Prestações de serviços efetuadas pelo sócio a uma sociedade abrangida pela } \\
\text { transparência fiscal }\end{array}$ & 1 & \\
\hline $\begin{array}{l}\text { Cessão ou utilização temporária de propriedade intelectual ou industrial; } \\
\text { outros rendimentos de capitais; resultado positivo dos rendimentos prediais; } \\
\text { saldo positivo entre mais/menos valias; restantes incrementos patrimoniais }\end{array}$ & & 0,95 \\
\hline Valor de aquisição dos incrementos patrimoniais obtidos a título gratuito & & 1 \\
\hline
\end{tabular}

*coeficientes são reduzidos em 50\% e 25\% no período de tributação do início da atividade e no período de tributação seguinte, respetivamente, desde que, nesses períodos, o sujeito passivo não aufira rendimentos das categorias $\mathrm{A}$ ou $\mathrm{H}$,

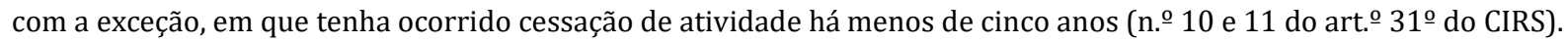

** Os coeficientes de 0,04 e de 0,10 são reduzidos em $50 \%$ e $25 \%$, no período de tributação de início de atividade e no

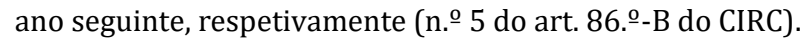

\subsection{Distinção entre os regimes simplificados de IRS e de IRC}

Perante as diferenças entre o regime simplificado em sede de IRS e IRC, apresentamos um exemplo ilustrativo que permite compreender as distinções entre o regime simplificado de IRS 
e o regime simplificado de IRC. Para um melhor esclarecimento do exposto, vamos dar continuidade ao exemplo ilustrativo anterior. Procederemos, também, à comparação dos resultados anteriormente obtidos - regime de contabilidade - com os resultados fiscais calculados para as mesmas estimativas nos regimes simplificados de tributação.

\begin{tabular}{|c|c|}
\hline & Hipótese 1 - Regime simplificado IRS \\
\hline \multirow{3}{*}{$\begin{array}{c}\text { Regime } \\
\text { simplificad } \\
0\end{array}$} & Rendimento tributável: $194.070,59 € \times 0,15=29.110,59 €$ \\
\hline & Acréscimo ao rendimento tributável (art. 31, n. 013 do CIRS): não aplicável. \\
\hline & Coleta: $(25.075 \times 24,967 \%)+(29.110,59-25.075) \times 37 \%)=7.753,63 €$ \\
\hline \multicolumn{2}{|r|}{ Total de imposto: $7.753,63 €$} \\
\hline \multicolumn{2}{|r|}{ Hipótese 2 - SUQ com distribuição de lucros sem opção pelo englobamento } \\
\hline \multirow{5}{*}{$\begin{array}{c}\text { SUQ } \\
\text { Regime } \\
\text { Simplificad } \\
\text { o }\end{array}$} & Matéria coletável: $194.070,59 € \times 0,04=7.762,82 €$ \\
\hline & Tributações autónomas: \\
\hline & Viatura ligeira de passageiros: $1.937,00 € \times 27,50 \%=532,68 €$ \\
\hline & Coleta: $7.762,82 € \times 17 \%=1.319,67 €$ \\
\hline & Total de imposto: $532,68 €+1.319,67 €=1.852,35 €$ \\
\hline \multirow{8}{*}{$\begin{array}{c}\text { Distribuiçã } \\
\text { o }\end{array}$} & Tributação do lucro distribuído, retenção na fonte: \\
\hline & Resultado Fiscal: $194.070,59 €-154.960,00 €-1.937,00 €-2.400,00 €-12.443,25 €-8.400,00 €=$ \\
\hline & $13.930,34 €$ \\
\hline & Valor distribuído: $13.930,34 € \times 70 \%=9.751,24 €$ \\
\hline & Retenção na fonte: $9.751,24 € \times 28 \%=2.730,35 €$ (art.. 71 do CIRS) \\
\hline & Rendimento categoria $\mathrm{A}$ \\
\hline & Rendimento coletável: $600,00 € \times 14$ meses $=8.400,00 €$ \\
\hline & Mínimo de existência - tributação: Zero \\
\hline \multicolumn{2}{|r|}{ Total de Imposto: $1.852,35 €+2.730,35 €=4.582,70 €$} \\
\hline \multicolumn{2}{|r|}{ Hipótese 3 - SUQ com distribuição de lucros com opção pelo englobamento } \\
\hline \begin{tabular}{|c|} 
SUQ \\
Regime \\
simplificad \\
o
\end{tabular} & Total de Imposto: $1.852,35 €$ \\
\hline $\begin{array}{l}\text { IRS do } \\
\text { sócio }\end{array}$ & $\begin{array}{l}\text { 8.400,00€ - 4.104,00€ }=4.296,00 € \text { (dedução específica da Categoria A) } \\
\text { 9.751,24€ x 50\%=4.875,62€ (50\% dos lucros distribuídos) } \\
\text { Rendimento Coletável: } 4.296,00 €+4.875,62 €=9.171,62 € \\
\text { Coleta Líquida: }(7.112 \times 14,5 \%)+(9.171,62-7.112) \times 23 \%)=1.504,95 €\end{array}$ \\
\hline & Total de Imposto: $1.852,35 €+1.504,95 €=3.357,30 €$ \\
\hline
\end{tabular}




\begin{tabular}{|c|c|c|c|c|c|c|}
\hline \multirow{3}{*}{$\begin{array}{l}\text { For } \\
\text { ma } \\
\text { Jurí } \\
\text { dica }\end{array}$} & \multicolumn{3}{|c|}{ Regime Geral } & \multicolumn{3}{|c|}{ Regime simplificado } \\
\hline & $\begin{array}{l}\text { Sem } \\
\text { distribuiçã } \\
\text { o de lucros }\end{array}$ & $\begin{array}{l}\text { Distribuição } \\
\text { de lucros - } \\
\text { sem } \\
\text { englobament } \\
\text { o }\end{array}$ & $\begin{array}{l}\text { Distribuição de } \\
\text { lucros - com } \\
\text { englobamento }\end{array}$ & $\begin{array}{l}\text { Sem } \\
\text { distribuição de } \\
\text { lucros }\end{array}$ & $\begin{array}{l}\text { Distribuição de } \\
\text { lucros - sem } \\
\text { englobamento }\end{array}$ & $\begin{array}{l}\text { Distribuição de } \\
\text { lucros - com } \\
\text { englobamento }\end{array}$ \\
\hline & $3.109,80 €$ & $5.840,15 €$ & $4.614,75 €$ & $1.852,35 €$ & $4.582,70 €$ & $3.357,30 €$ \\
\hline ENI & \multicolumn{3}{|c|}{$5.687,35 €$} & \multicolumn{3}{|c|}{$7.753,63 €$} \\
\hline
\end{tabular}

Para a SUQ, o regime simplificado de IRC admite uma maior poupança fiscal nos casos em que a SUQ não efetua a distribuição de lucros ou, se proceder à sua distribuição, decidir englobá-los. Estes são os dois casos em que o regime simplificado em sede de IRS é o mais vantajoso. 0 regime simplificado não é de todo benéfico para o contribuinte no caso de não optar pelo englobamento dos dividendos. Quanto ao regime geral, é o mais vantajoso para a SUQ se não efetuar a distribuição de lucros ou, se proceder à sua distribuição, optar pelo seu englobamento. No caso do ENI, o regime geral é, sem dúvida, o que contribui para uma maior poupança fiscal, como comprova a diferença de valor entre o regime geral e o regime simplificado.

\section{CONCLUSÃO}

A tributação dos rendimentos das empresas depende não só das regras aplicáveis no regime da contabilidade e no regime simplificado, mas também da forma jurídica adotada, empresa em nome individual ou sociedade unipessoal por quotas.

A escolha do regime fiscal é uma decisão que deve ser tomada no início de atividade e estar em conformidade com a forma jurídica adotada, podendo, contudo, depois de iniciada a atividade, ser alterada. A forma jurídica é, de facto, relevante para efeitos de determinação do regime fiscal aplicável em sede de IRS e IRC. Os resultados obtidos através do regime de contabilidade ou do regime simplificado são igualmente diferentes consoante é efetuada a distribuição de lucros e a ENI ou a SUQ decidir englobá-los ou não. Acresce ainda o facto de, em

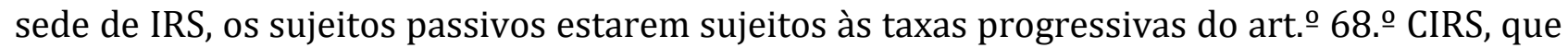
variam entre $14,50 \%$ para rendimentos até $7.112 €$ e $48 \%$ para rendimentos superiores a $80.882 €$, e em sede de IRC as taxas serem proporcionais, sendo a taxa geral de $21 \%$, podendo ser reduzida para $17 \%$ nos casos de empresas qualificadas como PME relativamente aos primeiros $25.000 €$ de lucro, aplicando-se a taxa de $21 \%$ para valores superiores.

Perante este quadro, é necessário que os empresários façam uma avaliação dos critérios fiscais, em termos de opção fiscalmente mais vantajosa, mas também em termos de matéria não fiscal, nomeadamente quanto aos custos de contexto inerentes ao desenvolvimento da atividade e da limitação da responsabilidade social. Nesta matéria, o empresário poderá responder pessoalmente pela totalidade do seu património no caso de fundada insuficiência 
dos bens penhoráveis do devedor principal e se tiver sido por culpa sua que o património da pessoa coletiva se tornou insuficiente para a sua satisfação.

Não existe uma regra geral aplicável a todos os casos, cabendo ao ENI/SUQ analisar cada caso em concreto e fazer uma simulação para ver o regime fiscalmente mais favorável. Os casos aqui apresentados neste estudo não podem ser generalizados, apenas devem contribuir para a compreensão desta problemática e servir de guião e de análise para outras situações reais.

\section{BIBLIOGRAFIA}

R. ALBERTO SANTOS COSTA, A Sociedade por Quotas Unipessoal no Direito Português, Almedina, Coimbra, 2002.

J. ANTUNES, "O regresso do regime simplificado em IRC", Jornal de Negócios, 2014.

A. C. BORREGO, C. LOPES \& C. FERREIRA, "A perceção dos Técnicos Oficiais de Contas sobre a complexidade e o cumprimento fiscal em Portugal: Resultados preliminares", Revista de Gestão dos Países de Língua Portuguesa, 15 (3), 65-83, 2016.

B. BRYS, S. MATTHEWS \& J. OWENS, Tax Reform Trends in OCDE Countries. OECD Taxation Working Papers, n.. 1, OECD Publishing, 2014. Disponível em: https://read.oecdilibrary.org/taxation/tax-reform-trends-in-oecd-countries_5kg3h0xxmz8t-en\#page1 [201907-23].

M. CARVALHO, Direito das sociedades comerciais (Capítulo 1), sumários desenvolvidos das aulas de Direito para a Economia e Gestão, Universidade do Minho, 2013. Disponível on-line em: https://repositorium.sdum.uminho.pt/bitstream/1822/25669/1/Direito\%20para\%20a\%20E conomia\%20e\%20Gest\%C3\%A3o\%20-\%20Cap.pdf

J. M. COUTINHO DE ABREU, Da empresarialidade. As empresas no Direito, Almedina, Coimbra, 1996.

J. M. COUTINHO DE ABREU, Curso de Direito Comercial, Vol. I, 10ª Edição, Almedina, Coimbra, 2017.

J.M. COUTINHO DE ABREU, Código das sociedades comerciais em comentário, Vol. I, Almedina, Coimbra, 2010.

V. CUNHA OLIVEIRA, Empresário em Nome Individual vs. Sociedade Unipessoal, Jornal Fiscal, 2001.

M.C. GASPAR ALVES, R. VIEIRA PORTELA \& P. SEGURO SANCHES, "Contributos para uma tributação simplificada das pequenas entidades", Tourism \& Management Studies, 8, 152-169, 2012.

C. LOPES, "Os custos de cumprimento das obrigações tributárias das Pequenas e Médias Empresas (PME) em Portugal", IV Conferência Internacional sobre os problemas contabilísticos e fiscais das PME, Ordem dos Técnicos Oficiais de Contas. Lisboa/Santa Maria da Feira, 30, e 31 de outubro de 2009.

C. LOPES, "Compliance costs of Corporate Taxation in Portugal", International Journal of Economics and Management Sciences, 1(10), 17-38, 2012.

A. MARTINS, “A Complexidade do Sistema Fiscal: Uma inevitabilidade?” Fisco, 119/121, 27-36, 2005.

R. MORAIS, Sobre o IRS, Almedina, Coimbra, 2006.

A. OLIVEIRA, A legitimidade do planeamento fiscal, as cláusulas gerais anti-abuso e os conflitos de interesses, Coimbra Editora, Coimbra, 2009.

R. TIAGO CONCEIÇÃO PEITO, A responsabilidade do sócio único, Universidade Católica Portuguesa Centro Regional do Porto, 2014, disponível on-line em:https://repositorio.ucp.pt/bitstream/10400.14/18228/1/A\%20RESPONSABILIDADE\%20DO\%20S \%C3\%93CIO\%20\%C3\%9ANICO\%20.pdf

J.L SALDANHA SANCHES, Os limites do planeamento fiscal: substância e forma no direito fiscal português, comunitário e internacional, Coimbra Editora, Coimbra, 2006.

A. C. SANTOS \& A. M. FERREIRA MARTINS, Relatório do Grupo para o estudo da política fiscal, competitividade, eficiência e justiça do sistema fiscal, Ministério das Finanças. Lisboa, 2009.

M. SEARA, O Regime simplificado de tributação em IRC - problemas de regime e de harmonização, Universidade Católica, 2014, disponível on-line em:

https://repositorio.ucp.pt/handle/10400.14/15888. 
1 Comissão Europeia (2006), A nove definição de PME. Guia do utilizador e modelo de declaração, Publicações "Empresas e Indústria", Comissão Europeia, p. 3.

${ }^{2}$ Consideram-se encargos relacionados com viaturas ligeiras de passageiros, motos e motociclos, nomeadamente, as reintegrações, rendas ou alugueres, seguros, despesas com manutenção e conservação, combustíveis e impostos incidentes sobre a sua posse ou utilização. 